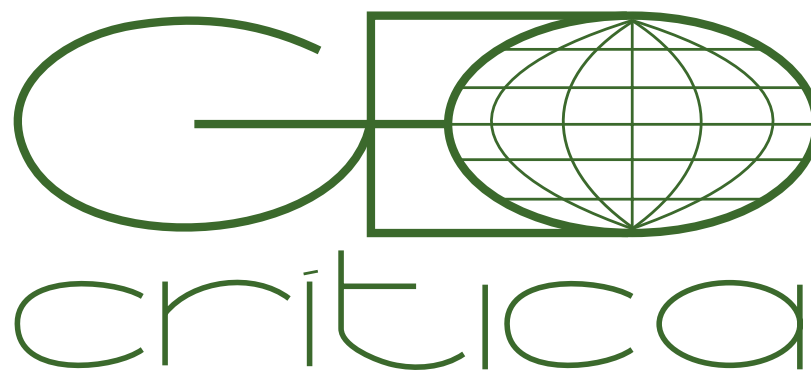

\section{Scripta Nova}

Revista Electrónica de Geografía y Ciencias Sociales Universitat de Barcelona

\title{
COLONIALIDAD DEL PODER, DESARROLLO URBANO Y DESPOSESIÓN MAPUCHE: URBANIZACIÓN DE TIERRAS MAPUCHE EN LA ARAUCANÍA CHILENA
}

\author{
Pablo Mansilla Quiñones \\ Instituto de Geografía. Pontificia Universidad Católica de Valparaíso, Chile \\ pablo.mansilla@pucv.cl \\ Walter Imilan Ojeda \\ Facultad de Arquitectura y Urbanismo, Universidad Central de Chile \\ walter.imilan@ucentral.cl
}

Colonialidad del poder, desarrollo urbano y desposesión mapuche: urbanización de tierras mapuche en la Araucanía chilena. (Resumen)

El crecimiento urbano de la ciudad de Padre Las Casas, en la Región de la Araucanía de Chile, en tierras indígenas mapuche tiene un impacto en el proceso de desterritorialización de sus habitantes indígenas. El presente texto describe los conflictos provocados por procesos de urbanización en comunidades mapuche. Se plantea que los conceptos de los estudios urbanos son insuficientes para abordar la transformación ontológica del suelo/territorio. Se exploraron conceptos de teorías decoloniales para develar las implicancias espacio culturales del proceso de expansión urbana y desterritorialización mapuche. Nuestra hipótesis es que más allá de elementos jurídicos institucionales que posibilitan la urbanización, ésta responde a concepciones de colonialidad del poder, del ser y estar que se aplican sobre la sociedad mapuche en la actualidad.

Palabras clave: colonialidad del poder, desarrollo urbano, desterritorialización, mapuche.

"Difusión de resultados del Proyecto Fondecyt Regular 1161437 (2016-2019) «Habitar en la ciudad intermedia: prácticas espaciales en Alto Hospicio y Padre Las Casas», y del Núcleo Milenio "Movilidades y Territorios", Iniciativa Milenio, Ministerio de Economía, Chile"

\section{Coloniality of power, urban development and mapuche dispossession: urbanization on mapuche land in chilean Araucanía. (Abstract)}

The urban growth of the city of Padre Las Casas on Mapuche indigenous lands has an impact on a deterritorialization process of indigenous inhabitants. The present text describes conflicts related to urbanization processes. We propose that the concepts of urban studies to explain the disputes in the expansion of the urban peripheries of Latin American cities, are insufficient to address the ontological transformation of the soil / territory. We explore the concepts of decolonial theories to reveal the cultural space implications of urban expansion process and Mapuche deterritorialization. Our hypothesis is that the urbanization process is supported by a colonial conception of power, of being and dwell over Mapuche Society, more than by institutional actions.

Keywords: coloniality of power, urban development, deterritorialization, mapuche. 
Lo "urbano" y lo "rural" se han identificado durante el siglo XX, en América Latina, como dos polos contrapuestos. Lo urbano, asociado con modernización capitalista y modos de vida modernos, mientras que lo rural queda como resabios de un mundo premoderno y hacendal, desconectado de los flujos de información y de circulación global del capital ${ }^{1}$. Los pueblos originarios han sido concebidos como parte del mundo rural campesino, incluso definidos por sus segmentos más excluidos de los procesos de modernización, aislados territorialmente y discriminados socialmente ${ }^{2}$.

La relación entre urbano y rural puede tener un símil entre la sociedad chilena Europa centrada y la mapuche replegada a la comunidad rural ${ }^{3}$. En efecto, en el siglo XX se consolida la visión de la expansión de la ciudad como inevitable progreso de la humanidad, una urbanización planetaria guiada por los principios del capital y de la modernidad occidental. Una visión triunfalista respecto a la urbanidad se impone en el discurso occidental ${ }^{4}$. Así, la tierra no-urbana se observa como un recurso para la expansión, inevitable destino deseado por la modernización capitalista. Junto con ella, la expansión urbana despoja a esos otros territorios de su propia historicidad y las formas de habitar que le han dado vida. Desde la temprana modernidad europea, lo urbano ha sido visto como condición de una modernidad hegemónica 5 .

La ciudad de Padre Las Casas, en el sur de Chile, se ha construido sobre tierras mapuche. En años recientes surgen resistencias que tensionan la expansión urbana sobre comunidades mapuche, varias de las cuales se encuentran bajo presión de urbanización. Se ha renovado una conciencia política respecto a la defensa de estas tierras a través del reconocimiento de su relevancia para el habitar mapuche, quebrando la ficción modernizadora de la tierra rural como simple recurso para la urbanización. Lo que emerge son antagonismos territoriales ${ }^{6}$, que refieren a ontologías distintas. La noción de tierra en mapuzungún (lengua mapuche) se suele traducir como mapu, no obstante, mapu se relaciona más con la noción de espacio, articulando las dimensiones física o material, social y simbólica ${ }^{7}$. Ser mapuche sólo es posible en la relación entre ser (che) y espacio (mapu). La tierra mapuche no es sólo suelo, por ello la expansión urbana se enfrenta a una distinción que va más allá de la noción de ruralidad tradicional. La dimensión de una "ontología otra" de los espacios de vida indígena en América Latina ha sido ampliamente discutida, pero no así en sus implicancias urbanas. El proceso que experimenta Padre Las Casas exige otra forma de problematizar la expansión urbana.

La construcción de infraestructuras de conectividad y proyectos inmobiliarios en esta comuna requiere desafectar la condición "indígena" de la tierra con el fin de urbanizar. Estos procesos se han desarrollado por caminos judiciales e instituciona-

1 Germani, 1976.

2 Bengoa, 2000.

3 Marimán et al, 2006

4 Contreras, 2016.

5 Berman, 1991.

6 Caniuqueo, 2005.

7 Quidel \& Jineo; 1999 
les espurios. En cierta forma, responden a una continuidad en la desposesión territorial iniciada por la ocupación militar chilena de la Araucanía de la segunda mitad del siglo XIX, seguida por legislaciones e ilegalidades durante el siglo XX sustentadas por el sistema judicial y político chileno.

El presente texto propone discutir críticamente el desarrollo urbano como práctica que surge en el contexto de la colonialidad del poder ${ }^{8}$. Es decir, lo urbano en cuanto sistema de negación de la existencia de formas de ser, saber y estar alternativas al proyecto de la modernidad ${ }^{9}$, imponiendo acciones que destruyen otras ontologías espaciales ${ }^{10}$. El análisis empírico que sustenta el presente texto se basa en dos casos. En primer término, se analizan las reclamaciones que surgen en el estudio para la implementación de un nuevo Plano Regulador Comunal de Padre Las Casas, el cual busca expandir el límite urbano. En segundo lugar, se expone la experiencia de desterritorialización de la comunidad Colimilla Burgos, a través de un análisis crítico de fuentes documentales del archivo histórico de tierras de la Corporación Nacional Indígena (CONADI), y de entrevistas en profundidad a habitantes de la comunidad. Estas permitem sistematizar percepciones, significaciones y valoraciones sobre conceptos como tierra, territorio y territorialidad. Adicionalmente, el análisis cuantitativo sobre información espacial contempló el uso de herramientas de análisis espacial vectorial mediante sistemas de información geográfica, utilizando funciones de superposición de polígonos, análisis de proximidad, distancia y cálculo de áreas.

La reflexión decolonial se ha desplegado a principios del presente siglo, a través de diferentes ámbitos de existencia de los pueblos originarios, renovando estrategias de lucha y construyendo nuevas subjetividades ${ }^{11}$. No obstante, el ámbito de las concepciones de lo urbano y urbanización ha sido insuficientemente estudiado desde esta perspectiva. En ese contexto, este artículo es una búsqueda por construir este campo en el contexto chileno, urgente y necesario por la realidad territorial de la Región de la Araucanía.

El texto posee cuatro apartados. Los dos primeros revisan teóricamente el concepto de colonialidad y propone un vínculo con la geografía y los estudios urbanos. El tercer apartado examina el desarrollo urbano y la colonialidad del poder en territorio mapuche a través de una revisión de aspectos históricos geográficos que marcan dicha relación. Finalmente, el cuarto indaga el caso de la comuna de Padre Las Casas y de la comunidad mapuche Colimilla Burgos. Los resultados de la investigación permiten comprender la cara de la colonialidad del poder expresada en el urbanismo neoliberal, cuyo discurso universalista, presente en su perspectiva de desarrollo urbano, niega la diferencia de los grupos sociales, su territorio y su territorialidad.

8 Quijano, 2000.

9 Farrés y Mataran, 2014.

10 Mansilla, 2017.

11 Clifford, 2018. 


\section{Colonialidad del poder y desarrollo urbano}

Comúnmente las expresiones territoriales de la colonialidad del poder en América Latina son estudiadas a través de los efectos del extractivismo de recursos naturales $^{12}$. Particularmente en territorio mapuche, sus efectos se evidencian en las marcas de la violencia estructural que se desprenden de los modelos de desarrollo forestal, minero e hidroeléctrico, entre otros. Estos generan conflictos y resistencias territoriales $^{13}$. Sin embargo, un aspecto poco discutido es el de los efectos de la colonialidad del poder ejercida por el desarrollo urbano sobre las tierras y territorio mapuche.

La colonialidad del poder, entendida como el sistema de clasificación étnico y racial, que "opera en cada uno de los planos, ámbitos y dimensiones, materiales y subjetivas, de la existencia social cotidiana y a escala societal"14, permite disponer de un marco interpretativo para el análisis de los efectos del desarrollo urbano sobre el habitar mapuche. En efecto, la dimensión territorial como ámbito fundamental de la existencia de los pueblos originarios se ve afectada en términos materiales y subjetivos por la práctica de la colonialidad. De forma tal que la clasificación social también forma parte de un sistema de clasificación espacial, que remarca formas diferenciadas de saber, ser y estar con el territorio ${ }^{15}$.

Hace algunas décadas, los estudios urbanos postcoloniales ${ }^{16}$ comenzaron a dar cuenta de las consecuencias del colonialismo europeo sobre ciudades en que establecieron sus regímenes de dominación. Como señala David Simon ${ }^{17}$, estas ciudades son lugares privilegiados para la reflexión entre el poder y la producción de espacio, debido a su condición como "centros de dominación y explotación política, militar y económica", así como también, lugares donde se ejercieron resistencias frente al colonialismo. Estos estudios encuentran una raíz en la reflexión del intelectual argelino Frantz Fanon ${ }^{18}$, quien describió inicialmente la fractura entre la ciudad "habitada por el colonizado" y la "ciudad colonial", como espacios diferenciados que remarcan una alteridad radical entre grupos sociales. En la perspectiva del autor, la ciudad colonizada o indígena es el lugar donde predomina la informalidad y la carencia, sus habitantes viven de cualquier manera y poseen mala fama. Para Fanon, la ciudad indígena se vuelve "un mundo sin intervalos, los hombres están unos sobre otros, las casuchas unas sobre otras". Por oposición se presenta la ciudad colonizada como el espacio ordenado y bien organizado, diseñado de manera armónica, donde sus habitantes viven de manera positiva acorde al estándar moderno.

Las investigaciones urbanas postcoloniales han descrito, por ejemplo, las transformaciones de las ciudades de África Sub-sahariana ${ }^{19}$, interrogando si las transformaciones en contextos postcoloniales han producido formas urbanas locales o si

\footnotetext{
12 Gudynas, 2014

13 Aylwin, 2000. Cuadra, 2015; Montalba, et al 2017.

14 Quijano, 2000.

15 Farrés y Matarán, 2014.

16 Yeoh, 2001.

17 Simon, 1989.

18 Fanon, 2009.

19 Simon, 1989.
} 
han tendido a la homogenización en el contexto de inserción en mercados globales. También, a propósuito de las disputas de apropiación por parte de los habitantes de un paisaje y arquitectura diseñados para introducir valores de la modernidad occidental ${ }^{20}$. De forma similar se ha discutido en torno a las ciudades asiáticas ${ }^{21} \mathrm{e}$ incluso canadienses para comprender la relación entre pueblos originarios y la urbanización del país de Norteamérica ${ }^{22}$. Sin embargo, la aplicación de la noción postcolonial ha sido objeto de crítica, debido a un uso extenso y a veces poco específico. Por lo tanto, los estudios empíricos son centrale ${ }^{23}$ para remover las convenciones epistemológicas con las que se aborda la ciudad contemporánea ${ }^{24}$.

Las ciudades latinoamericanas requieren formular su propia aplicación de la noción de colonialismo, muy diferente a la aplicada en los casos anteriormente citados. En Chile y Argentina, la historiografía clásica ha cerrado el período colonial con las "independencias" republicanas, invisibilizando un proceso de colonialismo estatal sobre los territorios, sociedades y cuerpos indígenas hasta la actualidad. Si bien este proceso podría ser entendido como uno de colonialismo interno ${ }^{25}$, es más preciso referirse a este como "colonialismo republicano", en cuanto son parte sustancial en la consolidación de los proyectos estado nacionales ${ }^{26}$.

El pensamiento decolonial ${ }^{27}$, particularmente en geografía ${ }^{28}$, convoca a renovar la teoría urbana ${ }^{29}$ en América Latina. El argumento para esta convocatoria es que los estudios urbanos han construido una dimensión territorial colonial al "establecer hegemónicamente una concepción del territorio sobre otras que resultan inferiorizadas" 30 , ejerciendo colonialidad del saber ${ }^{31}$, disponiendo de un conjunto de estrategias y dispositivos de poder que son ejercidos "en" y "a través" del espacio geográfico para el ejercicio de la dominación colonial ${ }^{32}$.

De forma general, es posible argumentar que la ciudad en Latinoamérica ha invisibilizado su bases indígenas, velando sus experiencias como despliegue de una forma de organización territorial moderna eurocéntrica y capitalista que define un modelo específico de organización y relación con el espacio geográfico. La idea misma de ciudad promueve una "jerarquía otorgada al 'ser urbano' sobre el 'ser no-urbano' como modelo de existencia" ${ }^{\prime \prime 3}$. De esta forma, se ejerce una colonialidad del ser,

20 Myers, 2014.

21 Bishop et Al., 2003.

22 Edmonds, 2010.

23 Yeoh, 2001

24 Ver Roy, 2004; Parnell y Robinson ,2012.

25 González - Casanova, 2017; Cusicanqui, 2012.

26 Menard y Pávez, 2007.

27 Se genera una distinción entre la discusión postcolonial y decolonial, por describir procesos de poder colonial diferentes, debido a las condiciones históricas y situaciones geográficas en las que surgen.

28 Do Carmo y Araújo de Oliveira, 2017; Radcliffe, 2017.

29 Farrés, 2014.

30 Ibid.

31 Castro Gómez, 2000; Rivera y Del Valle, 2016.

32 Mansilla, 2017.

33 Farrés y Matarán, 2014. 
es decir, una forma de poder que afecta la dimensión ontológica del territorio, cuyas expresiones se encuentran expuestas en la experiencia vividas de sujetos ${ }^{34}$, cuyas existencias territoriales son negadas al ser ubicados bajo la línea de la humanidad ${ }^{35}$. Las prácticas instaladas por este tipo de urbanismo moderno, colonial y capitalista forman parte de una perspectiva universalista que niega la diferencia en términos de producción del espacio, reproduciendo las asimetrías entre una cultura dominante y otra subalternizada, negando ontologías territoriales construidas desde la diferencia ${ }^{36}$.

En Latinoamérica, las implicancias de la colonialidad del poder sobre el territorio y la territorialidad han sido discutidas por diversos autores ${ }^{37}$ que cuestionan el modo en que el territorio en su dimensión material y simbólica representa uno de los sustentos del ejercicio de poder. El territorio es descrito como un concepto que engloba las manifestaciones de la colonialidad del poder, al saber con/en el territorio y de ser con/en el territorio. Desde esta perspectiva surge el concepto de "ontologías territoriales relacionales"38 para dar cuenta del territorio en cuanto fundamento de la existencia de actores humanos y no humanos que se encuentran en relación, y sobre los cuales recae la estructura de poder colonial ${ }^{39}$.

El territorio mapuche o wallmapu, ocupado militarmente por la república chilena desde mediados del siglo XX, fue colonizado mediante la construcción de fuertes militares, seguida de caminos y ciudades ${ }^{40}$. Pero es la completa relación de los diferentes elementos espaciales los que se vacían y resignifican; los bosques ya no son el hogar de fuerzas y espíritus vinculados a linajes familiares, sino que ahora se denominan recursos de explotación. La negación a otras formas de ser y estar en/con el territorio (colonialidad del ser y del estar) impone una forma única de conocimiento para organizar el territorio (colonialidad del saber territorial). Las ciudades son los enclaves desde donde se impone este horizonte temporal, eliminando aquellas formas territoriales consideradas "pretéritas" y retrasadas del territorio indígena.

Una revisión crítica de los estudios urbanos en Chile identifica la inadvertencia de su relación con los pueblos originarios ${ }^{41}$. Las investigaciones que exploran la relación entre pueblos originarios y lo urbano en Latinoamérica pueden ser agrupados en dos ámbitos. La primera son aquellas que indagan en procesos migratorios campo-ciudad y las prácticas de reterritorialización que los pueblos originarios despliegan en contextos urbanos. Dichas investigaciones son las que poseen mayor desarrollo, centrándose en comprender las implicancias que el cambio de lugar genera sobre las identidades culturales y las estrategias de resistencia cultural que

34 Maldonado Torres, 2007.

35 Grosfoguel, 2012.

36 Escobar, 2014.

37 Porto-Goncalvez, 2009; Haesbaert, 2012.

38 Blaser, 2014; Escobar, 2014.

39 Por ejemplo en trabajos desarrollados por Alimonda, 2011; Porto Goncalvez , 2009; Escobar, 2014.

40 Flores y Azócar, 2016

41 Brito, 2014. 
son desplegadas ${ }^{42}$. En cuanto a la segunda, se centra en el análisis del crecimiento urbano acelerado sobre tierras de pueblos originarios, así como sus implicancias sobre el territorio y la territorialidad. Entre estos trabajos, destacan investigaciones referidas a la urbanización de tierras de pueblos originarios andinos, en la ciudad de Quito $^{43}$, o el crecimiento urbano acelerado sobre los ejidos urbanos estudiados tempranamente en la Ciudad de México ${ }^{44}$. En Chile, los estudios se han concentrado exclusivamente en el primer conjunto de investigaciones. En ese marco es que a continuación se explora el caso de la comuna de Padre Las Casas, con el fin de evidenciar las implicancias de los discursos y prácticas asociadas al desarrollo urbano sobre las tierras de comunidades mapuche, dando cuenta de cómo efectivamente lo urbano genera formas de colonialidad del estar, negando la existencia de los pueblos originarios a partir de diversas estrategias.

\section{Desarrollo urbano de Padre Las Casas y expansión sobre tierras mapuche}

Los primeros pueblos y ciudades fundados durante la colonia española en territorio mapuche tuvieron como objetivo estratégico ejercer el control sobre la población. Para ello, provocaron su concentración territorial debido a que su condición semi-nómada dificulta el ejercicio de poder ${ }^{45}$. Una vez constituido el Estado nación chileno (y también el argentino), la colonialidad del poder implicó la continuidad de dominación sobre el pueblo mapuche. La fundación de ciudades y la consolidación de redes de transporte formaron parte de una estrategia para consolidar el dominio del Estado. Las ciudades continúan cumpliendo la misma función que tuvieron durante el periodo colonial español: colonización política y cultural sobre el territorio y sus habitantes ${ }^{46}$.

La anexión territorial de la Araucanía al estado implicó fuertes dinámicas económicas de intercambio que de cierta forma beneficiaron durante las primeras décadas a un segmento reducido de la sociedad mapuche a través de la formación de un mercado interno ${ }^{47}$. Al mismo tiempo, la expansión del mercado generó una presión sobre las tierras mapuche, en las cuales se llevaron a cabo una serie de procesos de enajenación por parte de privados. Las reducidas porciones de tierra en las que fue reducida la población y la sostenida enajenación por mecanismos ilegales precipitó el empobrecimiento económico de las comunidades y la migración de sus habitantes más jóvenes a ciudades ${ }^{48}$.

Los casos de Temuco y Padre Las Casas, tienen su origen en tiempos de la colonia española, en asentamientos irregulares de criollos que se localizan en tierras mapu-

42 Antileo, 2012; Imilan, 2014; Quintana, 2014; Sepúlveda y Zúñiga, 2015.

43 Brito, 2014.

44 Durand y Durand, 1983.

45 Correa y Mella, 2010.

46 Alvarado-Lincopi, 2015; León, 2007.

47 Pinto, 2011.

48 Imilán y Álvarez, 2008. 
che en la parte baja del cerro Konunwenu. Pero no será hasta el fin de la guerra de ocupación cuando se decide, por intereses militares, transformar ese asentamiento irregular en el centro del control sobre el territorio mapuche. A inicios del siglo XIX, el asentamiento de Padre Las Casas, localizado en la ladera opuesta a Temuco del río Cautín, era conocido como "Villa Alegre", debido a que concentraba una gran cantidad de bares y burdeles. Posteriormente, con la llegada de misiones católicas se quiso revertir la imagen negativa que tenía esta área. Para ello, intentaron evangelizar y traer "modernidad" a la población indígena con la fundación de escuelas dirigidas a los jóvenes mapuche de la zona. Adicionalmente, se implementó la ley seca, prohibiendo la venta y consumo de alcohol ${ }^{49}$.

El plano realizado por Nicanor Boloña a inicios del siglo XX (Figura $N^{\circ} 1$ ) presenta el pueblo de Padre Las Casas con una superficie de baja extensión y una estructura urbana compacta, manteniendo una relación de dependencia funcional con la ciudad de Temuco, donde se concentraba el trabajo y los servicios. Los predios alrededor del pueblo presentaban grandes extensiones de tierra con propietarios chilenos y mapuche.

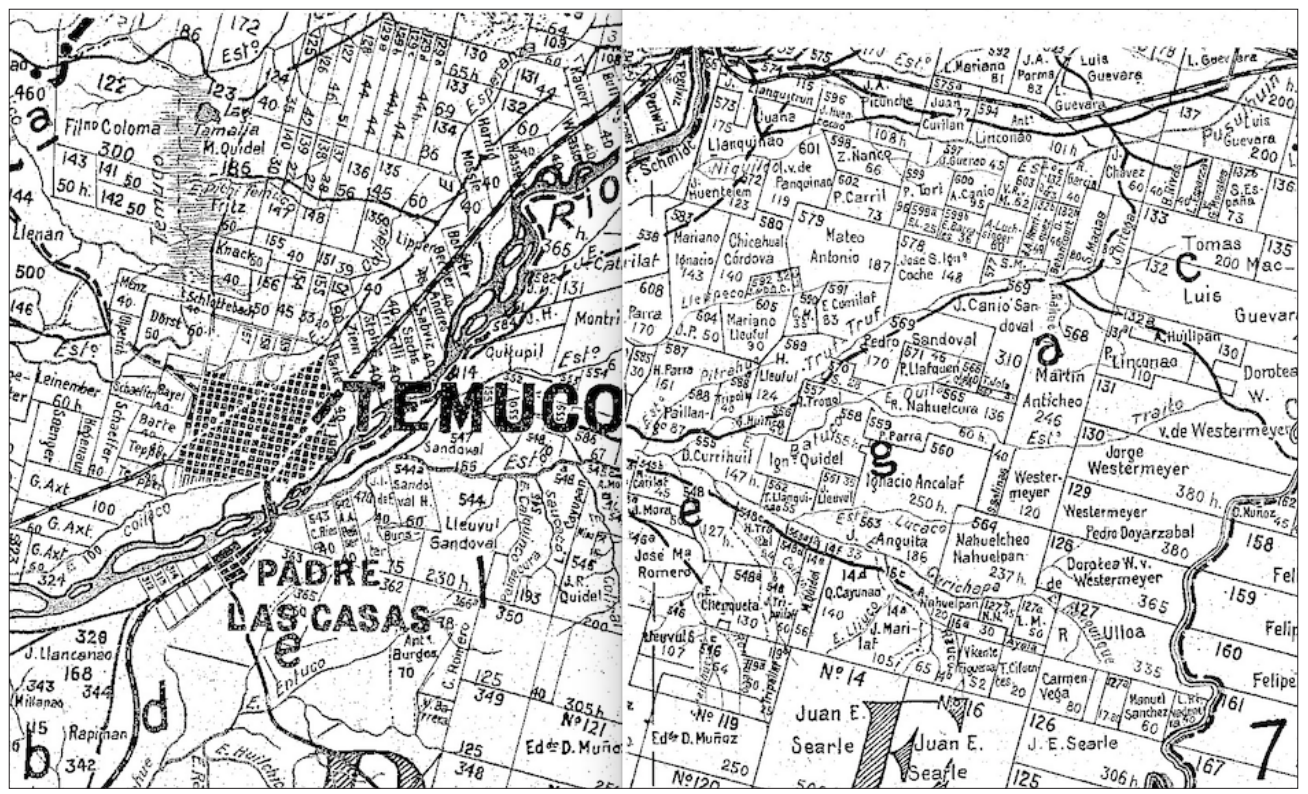

Figura N 1 Plano de Boloña, Provincia de Cautín.

Fuente: Plano Realizado por Nicanor Boloña año 1905. Dirección de Bibliotecas y Museos - DIBAM.

En aquella época se contabilizan en Padre Las Casas un total de 265 títulos de Merced o reducciones territoriales, que fueron entregados por la Junta Radicadora del Estado de Chile, entre los años 1894 y 1919. Estos se extendían en una superficie aproximada de 28.901 hectáreas, representando un 55,7\% de la superficie que actual de la comuna.

A lo largo del siglo XX se utilizan diversas estrategias para la expoliación de la

49 Documentos de 1962 señalan "Padre Las Casas ha sido siempre un sector muy difícil, hay muchas cantinas y negocios clandestinos de bebidas alcohólicas. La misión capuchina que existe allí no ha podido hacer mucho en este sentido, seguramente, falta algo que capte el interés de los pobladores que viven a continuación de este barrio, es decir, el sector rural". (Ministerio de Tierras y Colonización, 1962) 
tierra mapuche. En el área de Padre Las Casas las primeras enajenaciones de tierra se registran en 1928, a través de la Ley 4.332 dictada el 21 de junio de ese año, que ordenaba la expropiación de tierras en el sector de Maquewe para la instalación de una base militar, que en la década de 1960 se transformaría en el aeropuerto de Temuco.

La ciudad no pasará de ser un caserío articulado en torno a una calle principal, hasta la década de 1980. Por ese entonces, se inicia un proceso de erradicación de habitantes de asentamientos informales desde Temuco y otras ciudades del país. De esta forma se inició la construcción masiva de conjuntos habitacionales de vivienda social atraída por los relativos menores precios de suelo ${ }^{50}$. A partir de la década de 1990 la construcción de unidades de vivienda social se acelera, experimentando una variación de $47 \%$ en el número de viviendas entre el 1992 y $2002^{51}$ y alcanzando cerca de 50 mil habitantes en 2017. En la comuna se ha construido infraestructura vial que cruza un número significativo de tierras mapuche, entre las cuales destaca la construcción de una carretera bypass a Temuco y la instalación de nuevas vías urbanas que darán conectividad al nuevo puente que une Temuco y Padre Las Casas.

Este tipo de crecimiento en base a vivienda social se replicó en varias ciudades

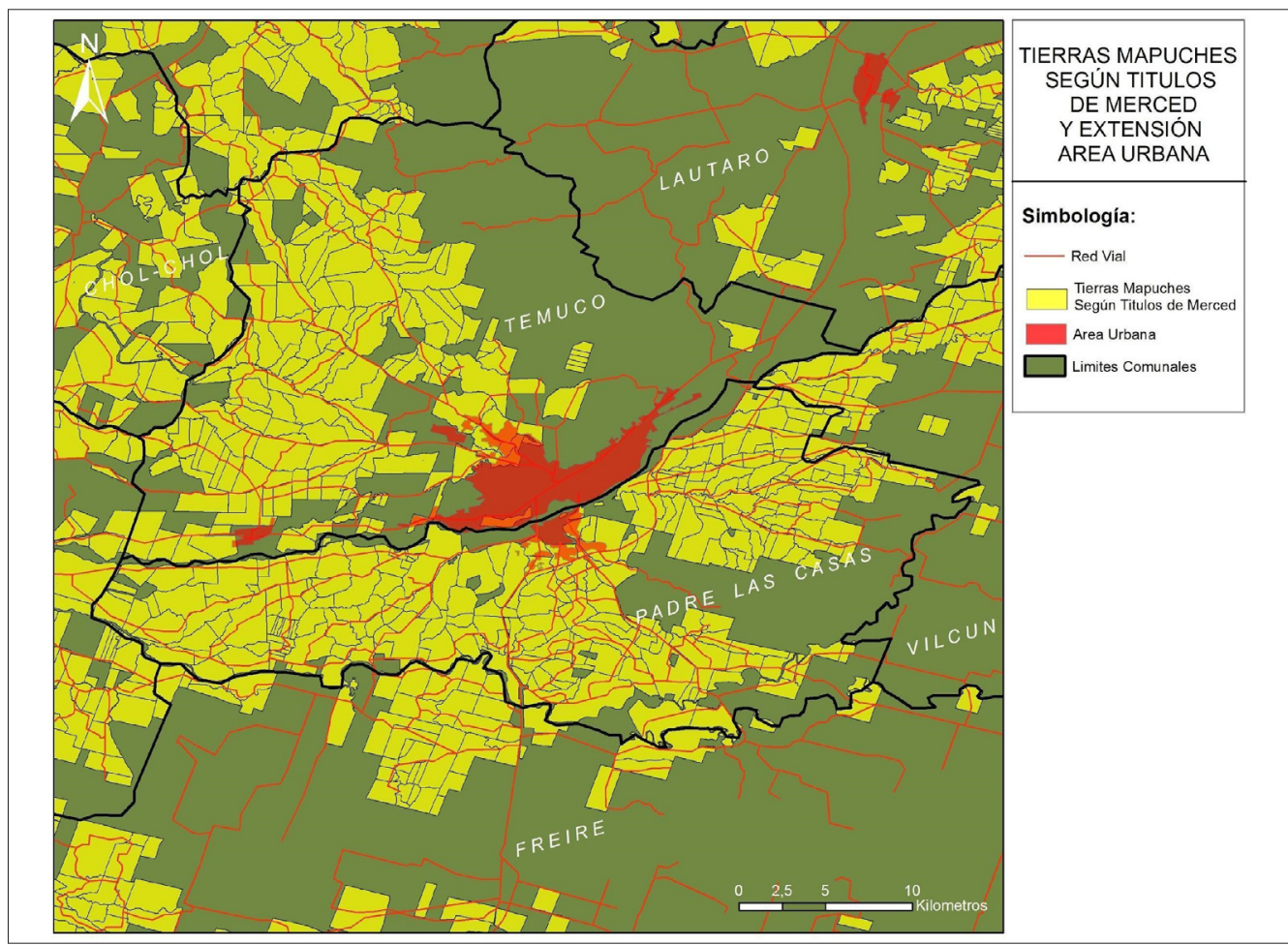

Figura 2. Superposición de Área Urbana y Tierras Mapuche con Título de Merced Fuente: Elaboración propia.

del país, generando una situación inédita pues, mientras se disminuye el déficit habitacional y se logra atender la demanda por vivienda por medio de la construcción masiva, la deficiente calidad habitacional y urbana genera nuevas vulnerabilida-

50 Peña y Escalona, 2009.

51 PLADECO Municipalidad de Padre Las Casas, 2012. 
des $^{52}$. El crecimiento de ciudades como Padre Las Casas ha sido insuficientemente discutido, ya que la crítica al modelo de vivienda chileno de cambio de siglo ha sido principalmente debatida en contextos metropolitanos y no de ciudades intermedias, como es el caso Temuco-Padre Las Casas.

En la Figura $\mathrm{N}^{0} 2$ se evidencia el carácter indígena de las comunas de Temuco y Padre Las Casas, en cuanto se evidencia una alta presencia de tierras con Título de Merced. En la Figura $\mathrm{N}^{0} 3$ se presenta el crecimiento urbano, durante el periodo 2003 al 2016 de Padre Las Casas, que se lleva a cabo sobre tierras mapuche. Hasta el 2003 la ciudad mantenía una estructura urbana que comenzaba incipientemente a transgredir los límites de estas tierras y ya en el año 2016 este proceso se hace mucho más significativo afectando, por lo menos, a ocho comunidades mapuche presentes en el periurbano de Padre Las Casas.

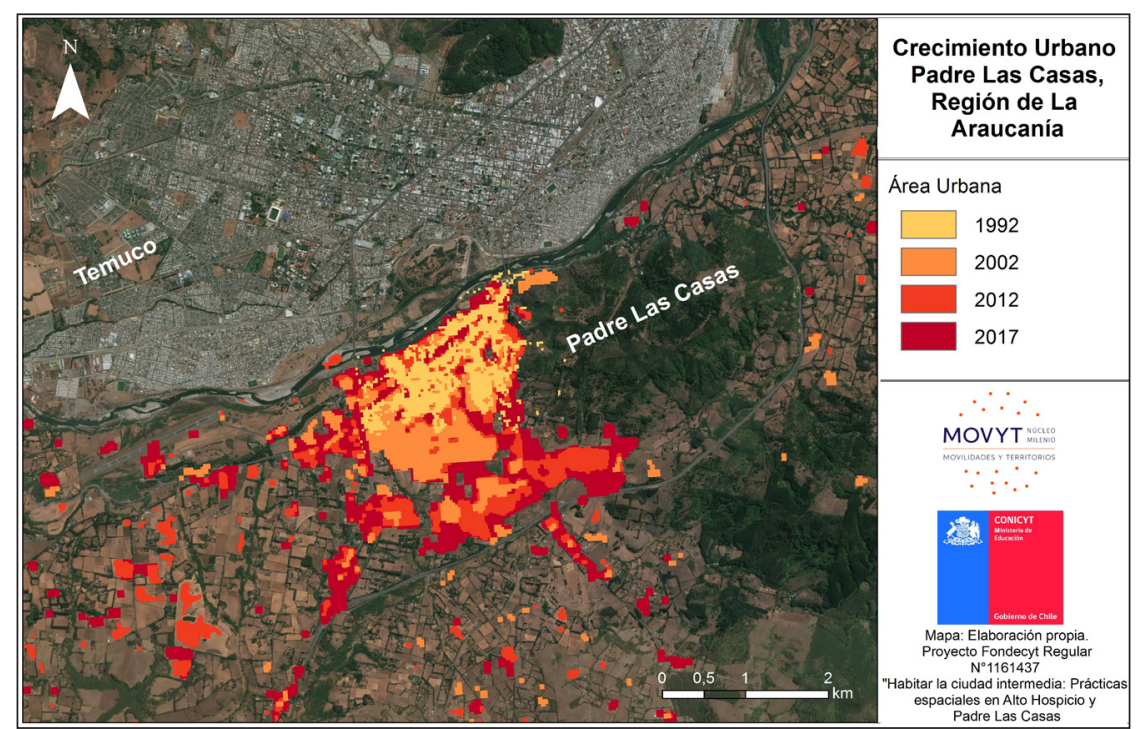

Figura $\mathrm{N}^{\circ} 3$ Crecimiento Urbano en la Comuna de Padre Las Casas, periodo $2003-2016$

Fuente: Elaboración propia.

Los conflictos que se han desprendido, a partir de este proceso, han quedado registrados en las memorias del estudio del último Plano Regulador Urbano de la comuna $^{53}$, en el que diversas organizaciones ciudadanas expusieron sus posiciones frente al desarrollo urbano presente y futuro de la comuna. Por ejemplo, la comunidad Bartolo Lepin, denuncia que en los alrededores de sus tierras existen terrenos que estarían siendo usados para construcción de vivienda social, lo que genera una presión sobre la comunidad y sus prácticas tradicionales, generando presión a salir del lugar que habitan. Del mismo modo, la comunidad mapuche Rafael Burgos denuncia que el nuevo Plan Regulador comunal establece como zona habitacional de

52 Imilan y otros, 2016; Rodríguez y Sugranyes, 2004.

53 Documento: "Observaciones realizadas por los vecinos de la comuna", forma parte del Plano Regulador

Comunla de Padre Las Casas, en: http://www.padrelascasas.cl/plc/plan_regulador.pdf (accedido 21-01-2019) 
densidad media y media baja, lo que traería severas consecuencias sobre las tierras comunitarias.

Otros casos indican conflictos de interés entre pobladores conformados en comités habitacionales y las comunidades mapuche, como es el caso de la comunidad mapuche José Nahuelñir, que denuncia al comité habitacional de pobladores "Las Vertientes" por encontrarse en terrenos que ancestralmente han pertenecido a la comunidad, motivo por el cual solicitan al municipio que no acepte la densificación habitacional, evitando la construcción de viviendas sociales que el comité quiere emplazar en el lugar.

En dicho estudio, el municipio declaró que los intereses de las comunidades Bartolo Lepin y Rafael Burgos son contrapuestos a los expuestos por la de Nahuelñir, quienes estarían de acuerdo con dar espacio al crecimiento urbano con fines habitacionales para densidad media. Sin embargo, en otro apartado del estudio se establece que la comunidad Bartolo Lepin reclama, que en los terrenos considerados por el Plan Regulador Comunal, como zonas de "Equipamiento jerárquico, Productivo, Habitacional", existe un Eltün (cementerio ancestral mapuche) en tierras de la comunidad indígena Rafael Burgos, en los que varias comunidades tendrían familiares enterrados. Al mismo tiempo, denuncian la afectación de su territorialidad y costumbres producto del avance urbano sobre los sitios de significación cultural tales como Nguillatuwe (centro ceremonial), cancha de Palin (Espacio para juego tradicional mapuche) y humedales, entre otros ${ }^{54}$, solicitando expresamente dejar en el Plan Regulador Comunal estas tierras en calidad de "zonas productivas", con el fin de evitar el desarrollo de otros proyectos a futuro.

Otro caso relevante es el expuesto por el Consejo Mapuche de Maquehue. En una carta al municipio, reclama que la Declaración de Impacto Ambiental (DIA) asociada al futuro Plan Regulador Comunal, pretende declarar "zona urbana" terrenos que actualmente están siendo reivindicados por el Consejo Mapuche de Maquewe y que han sido solicitados a la Corporación Nacional Indígena (CONADI) para ser adquiridos en el formato de "tierras en conflicto". Dichas tierras, que poseen una extensión aproximada de 275 hectáreas, se encontraban radicadas las reducciones Francisco Zenón Melivilu y Juan Llancanao, las que fueron expropiadas en 1928 mediante la ley $4.332^{55}$ que promovió la erradicación de tierras mapuche para el desarrollo urbano. Posteriormente, el 9 de enero de 1973, el gobierno de la Unidad Popular inscribió en el fisco las tierras expropiadas a las comunidades mapuche de Maquehue. Ese año, con fecha 13 de noviembre, acontecido el golpe militar del 11 de septiembre de 1973, se establece por decreto exento del Ministerio de Tierras y Colonización y del Ministerio de Bienes Nacionales, el traspaso de las tierras al Ministerio de Defensa Nacional, a través de la Fuerza Aérea de Chile para la construc-

54 Neira et al, 2012.

55 Ley del 21 de junio de 1928. 
ción del aeropuerto de Maquewe.

Todos estos casos expresan una alta conflictividad actual en la transformación de tierras indígenas en suelo urbano. Surge un nuevo escenario a partir de los planes municipales de la expansión urbana marcado por disputas que se remontan a los procesos históricos de producción territorial y que ahora, tendrían en comunidades organizadas un frente de defensa territorial.

\section{Avance urbano y desterritorialización mapuche: El caso de la comuni- dad Colimilla Burgos}

La comunidad mapuche Colimilla Burgos de la comuna de Padre Las Casas, es una de las que se ha visto más afectada por el crecimiento urbano y la producción de mega infraestructuras de movilidad. A lo largo del siglo XX una serie de procesos de captura de suelo urbano realizada por privados y el Estado han terminado afectando de forma significativa la tierra, el territorio y la territorialidad de esta comunidad.

Según consta en el Título de Merced $\mathrm{N}^{\circ} 363$, correspondiente a esta comunidad, el día 9 de enero de 1890 se presentó en la ciudad de Temuco, Colimilla Burgos para solicitar frente a la Junta Radicadora un Título de Merced de tierras para él y 31 personas más en el sector de Llahuallin. La radicación fue adjudicada ante la

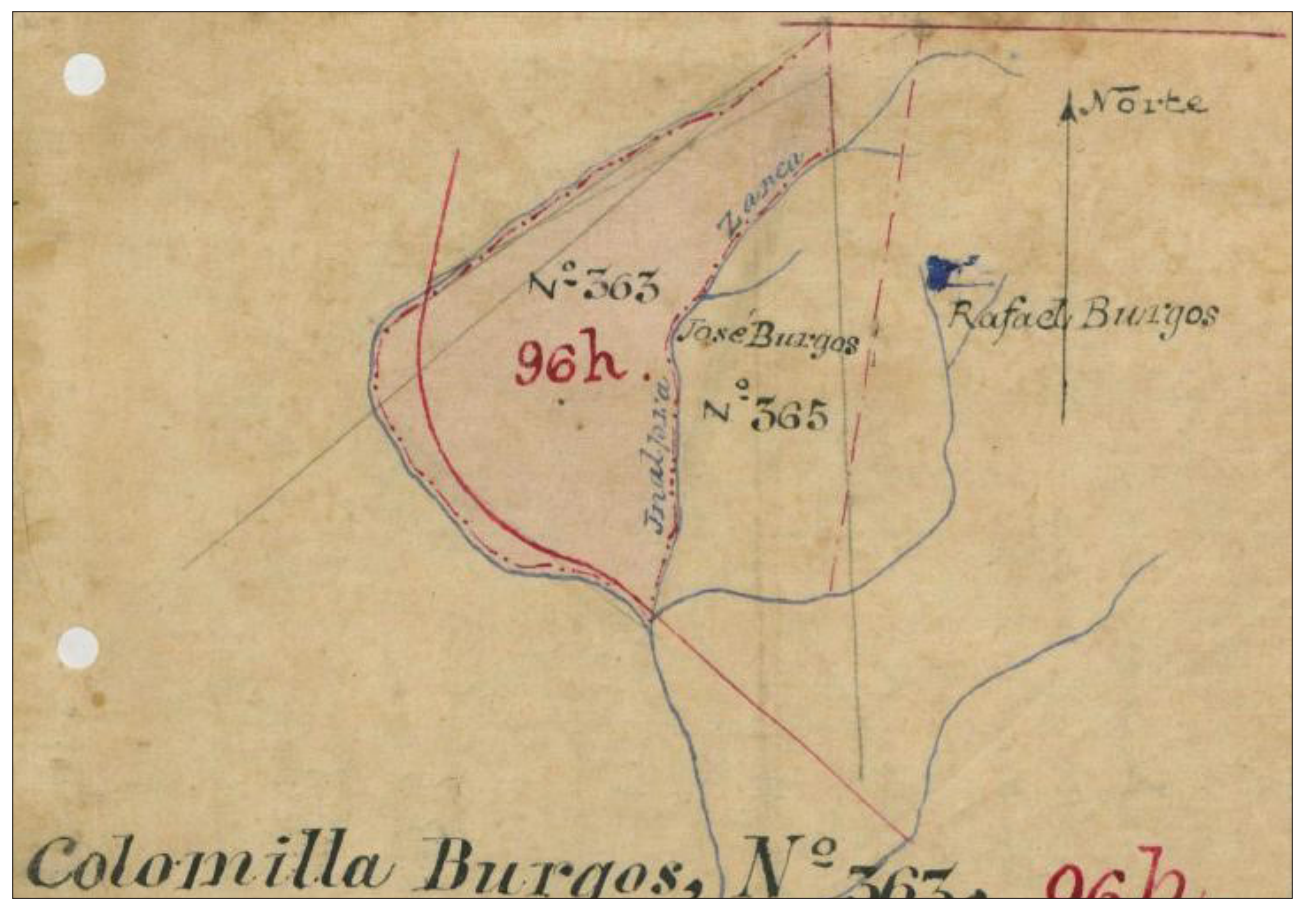

Figura $\mathrm{n}^{\circ}$ 4: Título de Merced de Tierra, Comunidad Colimilla Burgos Fuente: Archivo de Tierras, Comisión Nacional de Desarrollo Indígena - CONADI.

evidencia de posesión histórica de estas tierras, la carencia de medios de trabajo de los solicitantes, la buena calidad de los suelos para el desarrollo de cultivos y una coherencia entre el tamaño del predio y el conjunto de individuos que componían 
la comunidad.

En 1943 se produce la primera transformación de la comunidad a través del Decreto Supremo No 1530 del Ministerio de Tierras y Colonización que llevó a cabo la división de la propiedad comunitaria, por sentencia aprobada a través del Juzgado de Indios de Temuco. En total, 25 parcelas fueron entregadas a un número idéntico de familias parcelas con tamaños que varían entre 0,98 y 15 hectáreas. Esta subdivisión se enmarca en el contexto de una serie de leyes especiales sobre tierras indígenas, dictadas en los años 1927, 1930, 1931 y 1961, que facilitaron la división de las tierras mapuche que hasta ese momento se mantenían en propiedad comunitaria. La liquidación de comunidades y entrega de títulos individuales facilitó la enajenación y su posterior incorporación en el mercado de tierras ${ }^{56}$. Las tierras subdivididas dejaron de tener una protección especial, quedando expuestas a la ursurpación ${ }^{57}$. En términos fácticos, la comunidad Colimilla Burgos deja de tener existencia legal. Las consecuencias afectan de forma integral a la comunidad que habita estas tierras: problemas de productividad, pérdida de las funciones tradicionales de la comunidad y conflictos a raíz de diferentes accesos a la tierra, entre otros ${ }^{58}$.

Las consecuencias de estas políticas de fragmentación pueden ser evidenciadas en décadas posteriores. En el 1962, un informe del Ministerio de Tierras y Colonización ${ }^{59}$, realizó una encuesta en dicha comunidad con el fin de evaluar su situación social. Los resultados informaron que, de un total de 31 familias encuestadas, 9 eran adjudicatarias, 14 eran herederos o arrendatarios y las demás no tenían tierras, se encontraban allegadas o arrendaban sitios para levantar viviendas precarias. Las 31 familias ocupaban en total 61,10 hectáreas de superficie, trabajando anualmente alrededor de 22,75 hectáreas para la producción de hortalizas. Este informe da cuenta de la situación de desposesión que vive gran parte de las familias de la comunidad, quienes son descritas como personas vulnerables, que tan sólo tienen cultivos de subsistencia, con escasos animales y herramientas de trabajo junto a viviendas precarias. El mismo informe, además, diluye esta condición al afirmar que "estas familias ya no es posible clasificarlas dentro de las familias indigenas [negritas nuestras], pues, están totalmente incorporadas a la vida y costumbre de la clase trabajadora chilena. Se les ha encuestado, solamente por vivir en una ex-comunidad indigena". El informe concluye entregando una imagen de descomposición social basada en el aparente alcoholismo de los adultos y abandono de los niños, afirmando: "(...) son estos indigenas que por vivir tan cerca de la ciudad, han perdido toda su tradición y se han entregado a una vida inactiva y muy dada a las bebidas alcohólicas"60.

La precaria situación económica que enfrentaban las comunidades mapuche y las dificultades para el desarrollo agrícola motivaron el arriendo de tierras para la construcción de viviendas precarias a familias chilenas y mapuche que llegaban a

56 Aylwin, 2002.

57 ATM y CEPAL, 2012.

58 ATM y CEPAL, 2012.

59 A través de su dirección de Asuntos indígenas, zonal Temuco, el 31 de Agosto del año 1962.

60 Ministerio de Tierras y Colonización, 1967: 66. 
trabajar a Temuco. De esta forma, se inició un lento proceso de urbanización de los predios. La situación irregular, a través de la cual se inicia el asentamiento de pobladores en tierras de la comunidad, conducirá a una serie de conflictos entre estos asentamientos y los dueños indígenas por los arriendos impagos o los precios de venta.

En 1970, un incidente entre los miembros originales de la comunidad y un topógrafo del Ministerio de Vivienda y Urbanismo, quien debía levantar topografía de los terrenos para propiciar una expropiación para la construcción de vivienda social, se encuentra con la oposición de los habitantes. Al respecto, el profesional informa que "traté de levantar un plano de los terrenos antes mencionado, sencontrando total oposición por parte de los miembros de la ex-reducción Burgos Colimilla, aludiendo ser los dueños absolutos de los suelos y que no interesándose que se midieran, se oponían a este trabajo"61.

Durante la dictadura militar, Padre Las Casas también sufrió una serie de transformaciones urbanas que afectaron a las comunidades mapuche, principalmente relativas a la subdivisión de la propiedad comunitaria de la tierra mapuche, a través del Decreto de Ley 2.568 que permitía la entrega de títulos de dominio individuales y a la política de erradicación masiva de asentamientos informales en esa área, lo que vuelve a impulsar la presión sobre la tierra indígena.

Con el retorno a la democracia en 1990, la Ley Indígena 19.253 del año 1993 y actualmente vigente, intenta generar un freno a las usurpaciones de tierra mapuche a través de su congelamiento en el mercado de suelo, prohibiendo la compra de tierras por personas que no tienen calidad indígena. En el marco de esta Ley, la comunidad Colimilla Burgos registra nuevamente tensiones en relación con la propiedad de la tierra. Diversos mecanismos se establecen para la enajenación de tierra indígena para dar respuesta a la demanda por suelo urbano, uno de ellos se produce en 2014 cuando una propietaria, Manuela Burgos, alude a la cancelación de la calidad indígena de su tierra para poder ser vendida a empresas inmobiliarias. En este caso, se expone el siguiente argumento:

Doña Manuela Burgos Martínez no posee calidad de indígena [negritas nuestras], que sus apellidos no son indígenas, que no existe certificado alguno que acredite dicha calidad de indígena, que sus apellidos no son indígenas, que no existe certificados alguno que acredite dicha calidad, que nunca ha participado de costumbres ni forma de vida indígenas $(\ldots)^{62}$.

A través de este tipo de procedimientos se anula la condición indígena y, por lo tanto, su protección frente a otros usos no agrícolas o tradicionales mapuche, para dar paso a la construcción de vivienda social. En este caso, también se argumenta que al encontrarse las tierras dentro del Plan Regulador Comunal, su único destino posible, en cuanto suelo urbano, es el "de construcciones ya sea proyectos particulares o vivienda sociales. (...) [esta tierra] reuniría óptimas condiciones para ser destinado a fines habitacionales que benefician a un grupo considerable de personas que actualmente

61 Informe del topógrafo del Ministerio de Vivienda y Urbanismo, 30 de abril de 1970 62 Ibid 
se encuentran en situación de allegados"63.

En este mismo sentido, entre los años 2014 y 2017, de forma paralela a los intentos de desafectación de tierra indígena, el Ministerio de Vivienda y Urbanismo comienza a expropiar tierras de la comunidad Colimilla Burgos ${ }^{64}$ para destinarlo al proyecto de mejoramiento de la interconexión vial Temuco - Padre las Casas. En ese proceso gran parte de las familias fueron expropiadas. Sin embargo, una familia compuesta en su gran mayoría de mujeres, mantiene aún hoy oposición al proyecto, cuyos argumentos se exponen en el siguiente apartado.

\section{La desterritorialización en el relato de la comunidad}

Desde la perspectiva de los habitantes de la comunidad Colimilla Burgos emerge como un primer elemento el rápido proceso de crecimiento urbano de Padre Las Casas. Un primer aspecto que destaca en el discurso de las entrevistadas es el rápido proceso de crecimiento urbano de Padre las Casas y sus implicancias sobre tierras mapuche, el cual periodizan en cuatro momentos. El primero corresponde a la existencia de un pequeño poblado urbano rodeado por comunidades, donde se expresa que "el pueblo era una calle y lo demás puro campo, (...) yo digo cómo dejaron los mapuche aqui a la orilla del río, estaría como campo no más que no los botaron lejos, nos dejaron digo yo" (E.Q., 82 años). En ese periodo se registran transformaciones en la propiedad, como es señalado en este testimonio:

Mi abuelita alcanzó a vender una parte del terreno también, que se llama la 'Población Meza'. Ella alcanzó a vender ahí, pero la tierra no tenía valor en esos años, era campo pelado, más arriba había unos árboles (E.Q., 82 años).

El segundo proceso comprendió desde la década de los 1960, con la llegada de una gran cantidad de pobladores chilenos, que arrendaban tierras en comunidades mapuche y que con el tiempo se fueron asentando en el lugar. Como se señala en esta declaración, en que

después, en los 70, fue creciendo de a poco, que qué pasó, que la gente como estaba tan cerca de la ciudad no trabajaba mucho la tierra, empezaron a arrendar, entonces se empezaron a llenar como casitas por aquí, casitas por allá. Después, eso fue un problema, porque la gente hizo los pozos negros, el agua, la luz, entonces ahí la gente se unía para pedir al SERVIU esos adelantos. En eso el SERVIU no podía intervenir si no era urbanizado y no era de ellos. Así que hay otra expropiación (E.Q., 82 Años).

El tercer proceso urbano se encuentra vinculado a la reestructuración urbana que se generó en el marco de la dictadura militar y la promoción de vivienda social masiva, en la que incluso se registra la llegada de pobladores erradicados desde

63 Ibid.

64 A través del Artículo 51 Ley 16.391, DL 2.186/1978 y DS 1.128/2012 
asentamientos informales en Santiago de Chile. Así lo ratifican, en que

antes con Pinochet fue que salió la población Los Caciques. Ahí Los Caciques se formó con gente que venía de Pedro de Valdivia. Eso fue como una imposición, era que termina el campamento allá y creaban una población social acá. Seguramente era gente que estaba en toma, eran erradicaciones (A.Q., 52 Años).

El cuarto proceso de desarrollo urbano se origina a partir de la creación de la comuna de Padre Las Casas, como unidad político-administrativa independiente de la ciudad de Temuco.

Ya en el 1995 se creó la comuna, ya ahí en el 95, 96 empezó la administración y de ahí para delante se disparó. Debe ser la cercanía de Temuco, lo que más atrae al agente de Padre de las Casas y es como ciudad dormitorio también (A.Q., 52 Años).

Las entrevistadas comentan que efectivamente la pérdida de tierras es un proceso que se mantiene hasta la actualidad mediante expropiaciones impulsadas por el Estado para el desarrollo de vivienda social e infraestructura.

Sí, las expropiaciones las hacían para construir poblaciones, la de 'Huichague Sur', eso no fueron expropiaciones, la gente se juntaron, había un comité y empezaron a quedarse ahí, hasta que le tomaron expropiaciones (E.Q., 82 años).

Algunas de las familias una vez que fueron expropiados migraron hacia la zona cordillerana, como se indica en esta frase: "La gente se fue a la cordillera. Mi mamá tenía un tío que se llamaba Francisco Huenuman, él vendió y se fue a la cordillera, donde vendió están haciendo recién la población" (M.Q., 56 años)

Tal como es posible evidenciar, a partir del mapa expuesto en la Figura $\mathrm{N}^{\circ} 4$, las implicancias del avance urbano sobre tierras mapuche no sólo se expresan en la tenencia de la tierra, sino que también implican una profunda transformación de la territorialidad mapuche, es decir de su vínculo con el territorio en cuanto espacio de vida:

En el caso de los terrenos indígenas que están colindantes con la ciudad, es complicado, porque ya casi no pueden seguir haciendo vida normal, en el hecho de la siembra, los animalitos, se le pierden, la siembra también roba, ahora no se siembra nada (M.Q., 56 años)

También el avance urbano implicó un impacto significativo en el ámbito espiritual en relación al territorio mapuche, a través de intervenciones graves como la superposición de espacios de alto valor simbólico para las comunidades, lo que queda expresado en este testimonio:

El cementerio que había antiguamente desapareció, no respetaron nada, porque la municipalidad compró todo este pedazo, y la verdad es que nadie defendió eso, mi mamá tenía a su papá ahí, ella lo que hizo lo sacó y los llevó a Temuco, porque allá tenía a su mamá, así que 
sacó sus huesitos y se los llevó para allá (E.Q., 82 años).

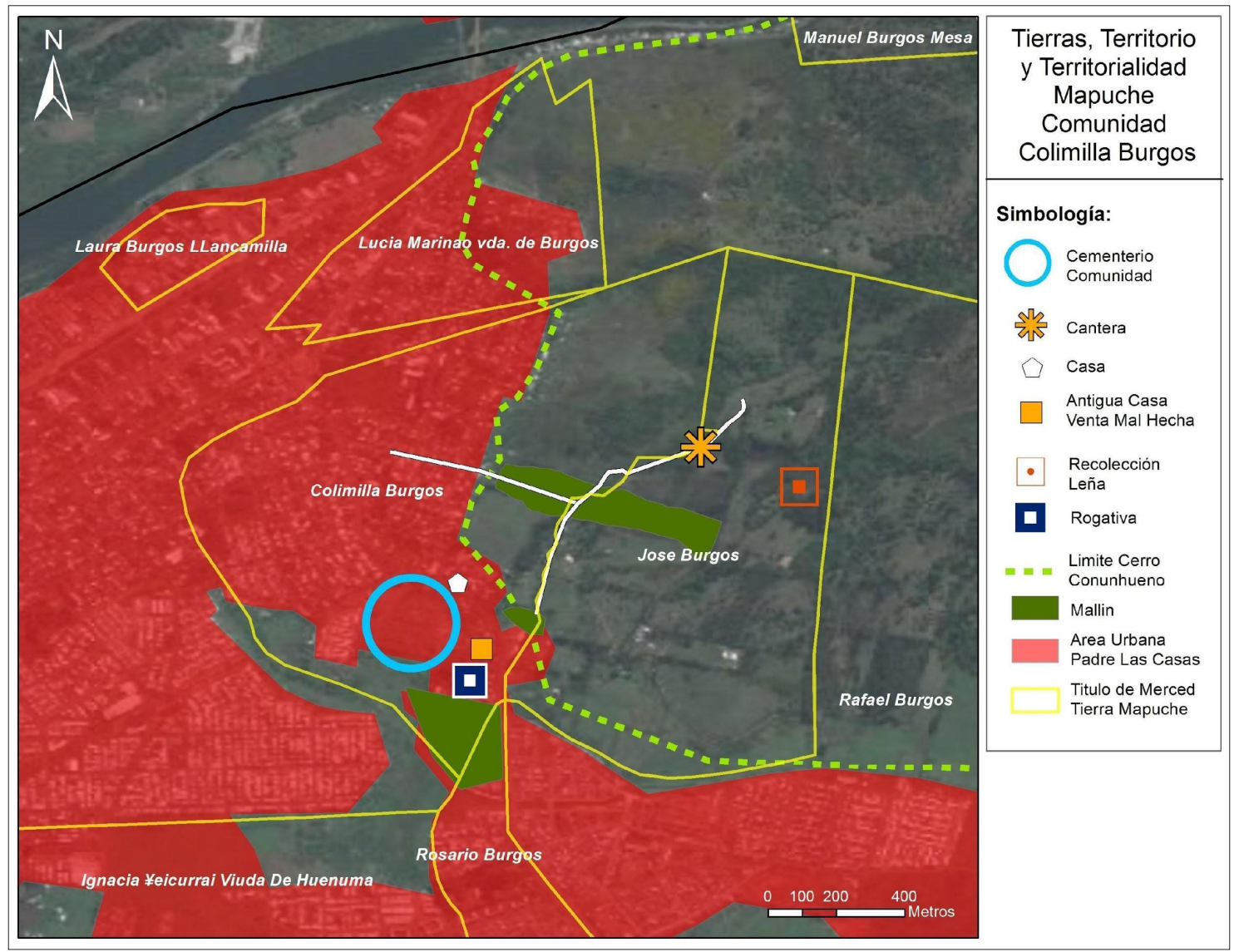

Figura $\mathrm{N}^{\circ}$ 5: Tierras, Territorio y Territorialidad Mapuche en la Comunidad Colimilla Burgos. Fuente: Elaboración Propia.

Al mismo tiempo, afectó profundamente las relaciones que las comunidades constituían con sus entornos naturales.

Había mallen, ahí salían los remedio, si había canelo, había de todo, un remedio que se busca que ya no hay, el menche... el que es bueno para el dolor de cabeza. Y así había yerba buena. Era una yerbita muy buena, las médicas la buscaban, a veces la recetaban y a la orillita de los bajos, donde no había animal, ahí se daban (E.Q., 82 años).

Otro aspecto relevante de destacar es la fragmentación territorial y comunitaria al interior de las comunidades provocadas por el desarrollo urbano, como se describe en el siguiente relato: "El hecho de separarnos, hemos vivido siempre juntos como comunidad y hoy en día estamos todos dispersos, entonces eso ha causado un daño sicológico, las personas a veces, que los que no lo viven pareciera que no existe, pero si existe" (M.Q., 56 años).

A la fragmentación comunitaria se suma un éxodo de población joven hacia la ciudad, lo que ha afectado el vínculo de pertenencia con el territorio y la continuidad familiar en las tierras ancestrales. "Los más jóvenes se fueron a vivir a la ciudad, entonces viven de otras actividades y la gente más vieja quedó en el campo, y la gente más 
vieja ya no puede trabajar, entonces ¿qué hace con su campo?" (A.Q., 52 años).

La negación del estatus indígena de los habitantes y de las tierras también se produce a nivel de instituciones del Estado, quienes inadvierten esta cualidad con el fin de apresurar procesos de expropiación, como consiga esta declaración:

Entonces el SERVIU nos contestó que para ellos no eran terrenos indígenas, así de simple, que éramos dueños particulares de sitios. Así que tuvimos que insistir, que éramos comunidad indígena con hacerles llegar planos, el Título de Merced y todo eso, así que realmente esto es terreno indígena, estaba en el archivo de los juzgados de los indígenas (M.Q., 56 años)

Las entrevistadas plantean el modo en que la idea de "desarrollo", asociado al avance urbano y promovida por parte de las instituciones del Estado, no considera las perspectivas de desarrollo a escala humana y mucho menos la noción de desarrollo desde la perspectiva mapuche, generando impactos emocionales que deben ser asumidos por la comunidad y sus integrantes.

Tú haces un proyecto de vida, una casa para un tiempo muy largo, y resulta que ahora, teníamos nuestras casas que las habíamos construido harán unos 10 años y ya las tenemos que dejar, el costo que eso significa, el sacrificio de haber construido y no poder hacer uso de lo que es tuyo y que te pasen a llevar, porque el Estado es el Estado y ... que por el desarrollo, tengas que perder lo que tú tienes, realmente es doloroso, es doloroso y complicado porque eso significa que tenemos que irnos a otro espacio (M.Q., 56 años).

\section{Conclusiones}

La producción de suelo urbano para la ciudad de Padre las Casas se ha llevado a través de la negación de la cualidad indígena de la tierra, territorio y territorialidad de las comunidades que habitan en su entorno. En el caso de las tierras de la comunidad Colimilla Burgos, se trata de una relación intensa entre las formas y significaciones de quienes las han habitado desde siglos, construyendo una espacialidad única. En la ficción teórica del desarrollo urbano de cuño funcionalista, la diferencia entre una hectárea rural y urbana está dada por lo que se puede "hacer" con ella, su productividad agrosilviopecuaria o su rentabilidad inmobiliaria, no reconociendo otras cualidades de carácter ontológicas.

Los mecanismos que se ponen en marcha desde la colonialidad del estar identificadas en el análisis empírico de documentos y entrevistas a miembros de dicha comunidad son: i) Estrategias de negación de la condición indígena de las tierras y de sus habitantes, que implica que los integrantes de comunidades mapuche no sólo sean presionados a vender sus tierras, sino que también tengan que negar su pertenencia al pueblo mapuche, y con ello negar apellidos y prácticas socioculturales. ii) La figura de expropiación de tierras, por parte del Estado, deviene en la forma más efectiva de liquidación de la propiedad de la tierra mapuche. En este sentido es importante destacar el rol de Estado en el contexto de desarrollo urbano capitalista de tipo neoliberal, el cual lejos de desaparecer, tiende a jugar un papel fundamental legitimando estos procesos a través de instrumentos legales que inciden en el ordenamiento territorial y facilitando la expropiación de tierras, así como también 
a través de la provisión de incentivos de inversión como subsidios o la instalación de infraestructura pública. Finalmente, iii) El ordenamiento territorial ha servido a modo de tecnología de las distribuciones espaciales mediante las cuales, se manifiesta el poder hegemónico (moderno y colonial) sobre el territorio y sus habitantes. Este ordenamiento desconoce la existencia de otras formas de uso y significado del territorio, amparándose en una supuesta racionalidad universal. En este sentido, el avance urbano reproduce un discurso de desarrollo universalista, que niega la diferencia y la existencia de otras maneras de habitar el territorio constituidas desde la historicidad del pueblo mapuche.

Hemos planteado que este proceso requiere ser observado y analizado más allá de los mecanismos tradicionales de transformación de suelo rural en urbano, con el cual opera el pensamiento urbano de cuño funcional estructuralista, reduciendo la tierra a la función que puede cumplir.

Si bien, la Ley Indígena y otros dispositivos legales, como el Convenio OIT 169, han reconocido las particularidades ontológicas de las tierras indígenas sometidas a la presión urbana, se vacía de esta condición, emergiendo nuevamente la colonialidad del poder que subordina hasta su desaparición estas otras ontologías geográficas en función de un tipo de colonialidad del estar, mediante la cual se señalan aquellas operaciones espaciales de carácter material e inmaterial que operan sobre y a través del territorio, promoviendo negaciones sobre las formas de "ser, saber y estar" con el territorio. Esta situación se distancia de la lógica del "multiculturalismo neoliberal" formulado por Hale, en el cual se reconocen derechos indígenas, siempre y cuando no colisionen con intereses del capital, más bien, se trata que desde la lógica de la urbanización no existirían derechos indígenas propiamente tales. Si bien, la población mapuche puede acceder a espacios ceremoniales u otras concesiones al interior de la ciudad para sus actividades, estas situaciones puntuales son "por merced" del Estado. Para el caso mapuche, la colonialidad del estar es ejercida por medio de operaciones espaciales que acompañan la urbanización. El crecimiento urbano va generando severos impactos sobre las comunidades mapuche, afectando la tenencia de la tierra y también su territorialidad, así como la completa vida cotidiana de la población.

Las reflexiones del presente texto llaman a discutir los fundamentos epistemológicos fuertemente enraizados en la tradición del conocimiento urbano eurocéntrico. Frente a ello, resulta evidente la necesidad de generar propuestas teóricas situadas que permitan aproximarnos a una lectura de las formas de estructuración del poder detrás de los procesos urbanos y territoriales, así como de las formas de desigualdad y exclusión que ocurren en nuestra América Latina.

En este sentido la colonialidad del poder y la colonialidad del estar, permiten dar cuenta de la cara oculta del urbanismo neoliberal, que no sólo se funda sobre la reproducción capitalista del espacio, sino que también corresponde a una produc- 
ción moderno colonial, que niega la diferencia y diversidad de ser con el espacio.

\section{Bibliografía}

ALIMONDA, Héctor. La colonialidad de la naturaleza Una aproximación a la Ecología Politica latinoamericana. Buenos Aires: CLACSO, 2011,331 p.

ALVARADO-LINCOPI, Claudio. "La Emergencia de La Ciudad Colonial En Ngülu Mapu: Control Social, Desposesión E Imaginarios Urbanos." In Wükan Ka Kuxankan Zugu Wajmapu Mew. Violencias Coloniales En Wajmapu, Temuco, Ediciones Comunidad de Historia Mapuche, ed. Comunidad de Historia Mapuche. Temuco, 107-40, 2015.

ANTILEO, Enrique. Nuevas formas de colonialismo: diáspora mapuche y el discurso de la multiculturalidad". Santiago: Tesis para optar al grado de Magister en Estudios Latinoamericanos, Universidad de Chile. 2012.

AYLWIN, José. Tierra y Territorio Mapuche: un análisis desde una perspectiva histórico jurídica. Chile: Universidad de La Frontera, 2002.

ATM y CEPAL. Desigualdades territoriales y exclusión social del pueblo mapuche en Chile: Situación en la comuna de Ercilla desde un enfoque de derechos.2012.

BISHOP, Ryan; PHILLIPS, John y Yeo WAI WAI. Postcolonial Urbanism: Southeast Asian Cities and Global Processes. Londres: Routledge, 2003.

BENGOA, José. Historia del pueblo mapuche:(siglo XIX y XX). Lom Ediciones, 2000.

BERMAN, Marshall. Todo lo sólido se desvaneces en el aire. La experiencia de la modernidad. Barcelona: Gedisa. 1991.

BLASER, Mario (2009). POLITICAL ONTOLOGY. Cultural Studies, 23 (5-6), 2009. p 873-896. https://doi.org/10.1080/09502380903208023

BRITO, M. L. Procesos de urbanización del Distrito Metropolitano de Quito y población indígena urbana. Pp. 75-106. En: Vivienda para pueblos indigenas en ciudades capitales andinas Procesos de urbanización y análisis de politicas urbanas. Laura Cedrés Pérez y Jaime Erazo Espinosa (Coords.). Quito: Programa de las Naciones Unidas para los Asentamientos Humanos, ONUHábitat Facultad Latinoamericana de Ciencias Sociales, FLACSO, 2014.

CANIUQUEO, Sergio. 2006. Siglo XX En Gulumapu. De La Fragmentación de La Wallmapu a La Unidad Nacional Mapuche, 1880 a 1979. En ;Escucha Winka! Cuatro Ensayos de Historia Nacional Mapuche y un epílogo sobre el futuro, (Eds) Marimán P.; Caniuqueo, S.; Millalén, J. y R. Levil, 129-217. Santiago: LOM. 2006.

CASTRO-GÓMEZ, Santiago. La colonialidad del saber: eurocentrismo y ciencias sociales: perspectivas latinoamericanas. Buenos Aires: CLACSO, 2000.

CLIFFORD, James. Returns: Becoming Indigenous in the Twenty-First Century. Harvard University Press, 2013.

ESCANDÓN, Christian Contreras. Hacia una nueva epistemología de la teoría urbana y arquitectónica. Estoa. Revista de la Facultad de arquitectura y 
Urbanismo de la Universidad de Cuenca, 2016, vol. 5, no 9, p. 91-97.

GUDYNAS, Eduardo. Conflictos y extractivismos: conceptos, contenidos y dinámicas. Revista en Ciencias Sociales, 2014, p. 27-28.

DO CARMO, W., \& Araújo de Oliveira, D. (Eds.). (2017). Geografia e giro descolonial: Experiências, ideias e horizontes de renovação do pensamento crítico (1st ed.). Rio de Janeiro: Letra Capital.

DURAND, Jorge. La ciudad invade al ejido: proletarización, urbanización y lucha politica en el Cerro del Judio, DF. 1983.

CORREA, Martín; MELLA, Eduardo. Las razones del illkun/enojo. Memoria, despojo y criminalización el en territorio mapuche, Observatorio Derechos de los Pueblos Indigenas, Santiago de Chile, Editorial LOM, 2010.

CUSICANQUI, Silvia Rivera. Violencias (re) encubiertas en Bolivia. Santander: Otramérica, 2012.

ESCOBAR, Arturo. Sentipensar con la tierra. Nuevas lecturas sobre desarrollo, territorio y diferencia. Colombia: Ediciones UNAULA (Colección Pensamiento vivo), 2014.

FANON, Frantz. Los condenados de la tierra. Buenos Aires: Fondo de Cultura Económica, 2009.

FARRÉS DELGADO, Yasser. Criticas decoloniales a la arquitectura, el urbanismo y la ordenación del territorio: hacia una territorialización de ambientes humanos en Cuba. Universidad de Granada, 2014.

FARRÉS DELGADO, Yasser; MATARÁN RUIZ, Alberto. Hacia una teoría urbana transmoderna y decolonial: una introducción. Polis (Santiago), 2014, vol. 13, no 37, p. 339-361.

FLORES, Jaime y AZOCÁR, Alonso. "Mapas para la el Estado. La representación de la Araucanía: 1836 -1916." Scripta Nova. Revista Electrónica de Ciencias Sociales XXI (562):1-37. 2016.

GERMANI, Gino. Causas y Consecuencias de La Urbanización Acelerada. Notas Sobre El Proceso de Urbanización En América Latina, en Urbanización, Desarrollo y Modernización, Ed. Germani, 264-77. Buenos Aires: Paídos. 1976.

GROSFOGUEL, Ramón. El concepto de «racismo» En Michel Foucault y Frantz Fanon: teorizar desde la zona del ser o desde la zona del no-ser. Tábula Rasa, 2012, no 16, p. 79-102.

GUDYNAS, Eduardo. Diez tesis urgentes sobre el nuevo extractivismo. Extractivismo, politica y sociedad, 2009, p. 187-225.

GONZÁLEZ - CASANOVA, Pablo. Explotación, Colonialismo Y Lucha Por La Democracia En América Latina. AKAL, 2017.

HAESBAERT, Rogério. El Mito de La Desterritorialización: Del Fin de Los Territorios a La Multiterritorialidad. México: Siglo Veintiuno, 2012.

IMILAN, Walter. Experiencia Warriache: espacios, performances e identidades mapuche en Santiago. En Poblaciones en movimiento. Etnificación de la ciudad, 
redes e integración, 2014, p. 254-278.

IMILAN, Walter; ÁLVAREZ, V. El pan mapuche. Aproximación a la migración mapuche en Santiago de Chile. Revista Austral de Ciencias Sociales, 2008, 14.

IMILAN, W.; Garcés, A. y Margarit D. (editores). Poblaciones en movimiento: etnificación de la ciudad, redes e integración. Santiago : Ediciones Universidad Alberto Hurtado, 2014. 278 p.

LEÓN, Leonardo. Tradición y modernidad: vida cotidiana en la Araucanía (19001935). Historia (Santiago), 2007, vol. 40, no 2, p. 333-378.

MALDONADO RIVERA, Claudio; DEL VALLE ROJAS, Carlos. Episteme decolonial en dos obras del pensamiento Mapuche: Re-Escribiendo la interculturalidad. Chungará (Arica), 2016, vol. 48, no 2, p. 319-329.

MALDONADO-TORRES, Nelson. Sobre la colonialidad del ser: contribuciones al desarrollo de un concepto. El giro decolonial. Reflexiones para una diversidad epistémica más allá del capitalismo global, 2007, p. 127-167.

MANSILLA, Pablo. Geografías del No Ser: La invención de la Zona Roja del Conflicto Mapuche. En: Las Otras Geografías en Chile. Andrés Nuñez, Enrique Aliste y Raúl Molina (Eds.). Santiago de Chile: LOM, 2018.

MARIMÁN, Pablo; CANIUQUEO, Sergio; MILLALÉN, José y Rodrigo LEVIL. 2006. i...Escucha, Winka...!. Cuatro Ensayos de Historia Nacional Mapuche y Un Epílogo Sobre El Futuro. Santiago: LOM, 2006.

MOLINA, Raúl; AYLWIN, J. Geografías mapuches: territorios, política y desafíos en tiempos de cambio. Revista geográfica del sur, 2013, vol. 3, no 1, p. 15-36.

MONTALBA, René et al. Determinación de las fuerzas conductoras de la transformación ambiental de la Araucanía chilena: El "paisaje cultural" como marco de análisis. Diálogo Andino. 2017, 54, pp.51-61

MUNICIPALIDAD DE PADRE LAS CASAS. Estudio Plan Regulador Comunal Comuna Padre Las Casas. 2012. Padre Las Casas: Municipalidad de Padre Las Casas.

MYERS, Garth. Colonial and Postcolonial Modernities in Two African Cities. Canadian Journal of African Studies / Revue Canadienne Des Études Africaines, 37(2-3), 328-357. 2003

NEIRA CEBALLOS, Zoia, et al. Espacios ecológico-culturales en un territorio mapuche de la región de la Araucanía en Chile. Chungará (Arica), 2012, vol. 44, no 2, p. 313-323.

PARNELL, Susan; ROBINSON, Jennifer. (Re) theorizing cities from the Global South: Looking beyond neoliberalism. Urban Geography, 2012, vol. 33, no 4, p. 593-617.

PEÑA-CORTÉS, Fernando y ESCALONA-ULLOA, Mario. Expansión urbana en la intercomunal Araucanía Centro. Alteraciones sobre las áreas rurales. Chile del país urbano al país metropolitano, 2009, p. 389-398.

PINTO RODRÍGUEZ, Jorge. Expansión económica y conflicto mapuche. La Araucanía, 1900-1940. Revista de Historia Social y de las Mentalidades, 2011 , vol. 
1 , no 11 .

PORTO-GONÇALVES, Carlos Walter. De saberes y de territorios: diversidad y emancipación a partir de la experiencia latinoamericana. Polis (Santiago), 2009, vol. 8, no 22, p. 121-136.

QUIDEL, José \& JINEO, Fernando. Las raíces para nuestro cultivo; en Caro, Aracely Y Duran, Teresa \& Tereucan, Julio (Eds.), Estilos desarrollos en América Latina. Identidad -Cultura-Territorio-Medio Ambiente. Un aporte para la discusión. Universidad de la Frontera; Temuco-Chile. 1999.

QUIJANO, Anibal. Colonialidad del poder, eurocentrismo y América Latinal. In CLACSO (Ed.), La colonialidad del saber: eurocentrismo y ciencias sociales. Perspectivas latinoamericanas. Buenos Aires: CLACSO, 2000.

QUINTANA, Jenniffer Thiers. Santiago Mapuche. La dimensión indígena del espacio urbano en Chile. Scripta Nova. Revista Electrónica de Geografía y Ciencias Sociales, 2014, vol. 18.

RODRIGUEZ, Alfredo; SUGRANYES, Ana 2004. El Problema de Vivienda de Los 'Con Techo.' EURE, 2004, 30 (91):53-65.

ROY, Ananya. Las metrópolis del siglo XXI: nuevas geografías de la teoría. Andamios, 2013, vol. 10, no 22, p. 149-182.

YEOH, Brenda. Postcolonial cities. Progress in Human Geography, 25(3), 456-468. 2001.

SIMON, David. ( 1989). Colonial cities, postcolonial Africa and the world economy: a reinterpretation. International Journal of Urban and Regional Research, 13(1), 68-91. 1989.

SEPÚLVEDA, Bastien; ZÚÑIGA, Paulina. Geografías indígenas urbanas: el caso mapuche en La Pintana, Santiago de Chile. Revista de Geografía Norte Grande, 2015, no 62, p. 127-149.

WALLERSTEIN, Immanuel Maurice. Geopolitica y geocultura: ensayos sobre el moderno sistema mundial. Editorial Kairós, 2007.

(c) Copyright: Pablo Mansilla Quiñones, 2020

(c) Copyright: Scripta Nova, 2020.

Ficha bibliográfica:

MANSILLA QUIÑONES, Pablo. Vivienda y movilidad. Colonialidad del poder, desarrollo urbano y desposesión mapuche: urbanización de tierras mapuche en la Araucanía chilena. Scripta Nova. Revista Electrónica de Geografía y Ciencias Sociales. Barcelona: Universidad de Barcelona, 15 de enero de 2020, vol. XXIV, $\mathrm{n}^{\circ}$ 630. [ISSN: 1138-9788] 